\title{
Analyzing Pedestrian Perceptions towards Traffic Safety Using Discrete Choice Models
}

\author{
Dewa Made Priyantha Wedagama ${ }^{\mathrm{a}}$, Sahan Bennett ${ }^{\mathrm{b}}$, Dilum Dissanayake ${ }^{\mathrm{c}}$ \\ ${ }^{a}$ Department of Civil Engineering, Udayana University, Kampus Bukit Jimbaran, Badung-Bali, 80361, Indonesia \\ E-mail: priyantha@civil.unud.ac.id \\ ${ }^{b}$ College of Medicine, Glasgow University, Wolfson Medical School Building, Glasgow, G12 8QQ, The United Kingdom \\ E-mail:2297090B@student.gla.ac.uk \\ ${ }^{c}$ School of Engineering, Newcastle University, Cassie Building, Newcastle upon Tyne, NE1 7RU, The United Kingdom \\ E-mail: dilum.dissanayake@ncl.ac.uk
}

\begin{abstract}
Policymakers and national, regional, and local authorities will require to cater to growing demands for public services and facilities, including the implementation of better and safer infrastructure. This should be conducted focusing on the urban poor and other vulnerable groups for their basic needs for transportation, housing, education, health care, and, more importantly, a safe and liveable urban environment. Meanwhile, pedestrians are often the most vulnerable road users in society, so investigating pedestrian accidents' causes and consequences is essential. Like neighboring countries in Asia, Indonesia experiences a high pedestrian fatality rate. This study investigates pedestrian perceptions toward traffic safety and identifies novel measures to improve pedestrian safety, with a particular focus on developing cities. Data collection involved self-reporting using questionnaires by respondents based in Denpasar, the capital city of Bali Province. Binary and multinomial logit models were estimated using pedestrian perception data to identify the factors that influence pedestrian accidents. This study found that reckless or careless driving/riding contributed significantly to pedestrian accidents at both night and day times. Besides, junctions and pedestrian crossings were perceived to be dangerous for pedestrians compared to other road infrastructure such as footpaths. The outcome of the study also reveals that motorcycles will be more influential for pedestrian accidents than cars. To reflect upon the findings, some countermeasures for enhancing pedestrian safety in Denpasar were discussed with attention to engineering, policy, enforcement, and education perspectives.
\end{abstract}

Keywords — binary logit; multinomial logit; pedestrian; perceptions; traffic safety.

\section{INTRODUCTION}

According to the United Nations' recent statistics, 55\% of the world's population lives in urban areas as of 2018; this share is expected to increase to $68 \%$ by 2050 . Projections also show that nearly $90 \%$ of this increase will occur in the global south in general, Asia, and Africa in particular [1]. As cities and urban areas are subjected to rapid growth and urbanization, policymakers and national, regional, and local authorities will require to cater to growing demands for public services and facilities, including better and safer infrastructure. This should be done focusing on the urban poor and other vulnerable groups for their basic needs for transportation, housing, education, health care, and, more importantly, a safe and liveable urban environment. This study mainly focuses on road safety aspects with attention to pedestrians. Pedestrians are often the most vulnerable road user group in our society, so investigating pedestrian accidents' causes and consequences is essential [2]. Previous research on pedestrian safety covered various aspects involving child pedestrians [3], [4], gender aspects [5], and perceptions across many countries in Europe [6]. The pedestrian safety research in developing countries has been receiving considerable attention in recent years, for instance, in India [7], in the Philippines [8], and in China [5], [9].

Both actual and perceived risks are essential when achieving road safety targets, in which safety is not just about being safe but also feeling safe [10]. Therefore, exploring pedestrian attitudes and perceptions will help generate understanding amongst decision makers of safety requirements and allow the development of strategies and the implementation of appropriate measures to make sure that the safety targets will be achieved.

According to Indonesia's most recent statistics, pedestrian fatalities contributed to $40 \%$ of the total road fatalities in 
Indonesia [11]. When compared to neighboring countries in Asia, similar figures were noted, for example, Bangladesh (41\%), China (25\%), Pakistan (41\%), Sri Lanka (32\%), and India $(40 \%)$ [11]. The high pedestrian fatality rate is due to the speed of passing vehicles on pedestrian areas, lack of footpaths, lack of crossing provision for pedestrians with associated speed control and warning signage for vehicles, and vehicles failing to give way to pedestrians [12]. Therefore, pedestrians are considered one of the most vulnerable road user groups in developing countries where their safety has been given inadequate attention from the policymakers [5], [7]. Previous research mainly focused on analyzing pedestrian accidents based on the country-based statistics and accident datasets collected by police authorities.

Some attention originated from the developed world about pedestrian perception since the late 1990s [13]-[15]. In contrast, only a few studies focus on pedestrian perception, particularly from developing countries in Asia and Africa [8], [9], [16]. Some pedestrians preferred not to use crossing facilities, instead of crossing roads illegally from random locations, because they did not think the facilities can meet their demands [16].

Accident locations, the primary transportation mode, time of accidents, and a significant cause for accidents have been given attention in pedestrian safety research [7], [17], [18]. Additionally, other demographic variables, such as age and gender, have also been considered in pedestrian accident studies [19], [20]. Therefore, the factors that have been identified in the previous research will be given adequate attention in this study.

This study will lead to generating some fundamental understanding of the contributory factors that influence pedestrian safety, considering Denpasar, the capital city in Bali, as the case study area. Besides, it provides insight into the influencing factors on pedestrians' characteristics and perceptions towards pedestrian accidents. Increased awareness of pedestrians' perceptions towards the measure of pedestrian accidents will allow the promotion of educational and enforcement initiatives aiming to improve pedestrian safety. In addition, some useful information can be shared with pedestrians as an attempt to achieving safer walking. In other words, it is expected that pedestrians may use the knowledge gained to make positive changes in their travel activities. This study provides some understanding of safety problems from pedestrians' standpoint and essential information on components affecting pedestrians traffic accidents.

This paper aims at analyzing pedestrians' perceptions of traffic safety by constructing binary and multinomial logit models. With the constructed model, pedestrians' perceptions of traffic safety are examined in mixed traffic conditions. This paper begins with a research methodology in Section 2. In Section 3, data analysis using discrete choice methods is described. Finally, the paper draws conclusions and makes recommendations in Section 4.

\section{MATERIALS AND METHOD}

\section{A. Data Collection}

A cross-sectional survey, using a self-reported questionnaire design, was deployed for pedestrians in
Denpasar, Bali's capital city. This methodology was in line with a previous study [21], showing that it is appropriate to consider self-reported perception. It showed a stable perception pattern and predicted a consistent indicator of future intentions of behavior. The questionnaires were distributed to 400 randomly selected pedestrians living in Denpasar in June-July 2017. Due to missing data, however, only 310 samples (77.5\% of the total number of samples) were considered during the analysis

TABLE I

DETAILS OF THE QUESTIONNAIRE

\begin{tabular}{|c|c|}
\hline \multicolumn{2}{|c|}{ I. Socio-demographic factors } \\
\hline P11 & Gender $($ Male $=1 ;$ Female $=2)$ \\
\hline P12 & $\begin{array}{l}\text { Age }(<20 \text { years old }=1 ; 20-29=2 ; 30-39=3 ; 40-49=4 ; \\
>50=5)\end{array}$ \\
\hline P13 & $\begin{array}{l}\text { Household income }(<3 \text { million }=1 ; \geq 3 \text { million }=2 ; \text { no } \\
\text { answer }=3 \text { ) }\end{array}$ \\
\hline P14 & Driving license ownership $(\mathrm{Yes}=1 ; \mathrm{No}=2)$ \\
\hline P15 & $\begin{array}{l}\text { Primary mode of travel }(\text { Car driver }=1 ; \text { Car passenger } \\
=2 ; \text { Bus \& taxi }=3 ; \text { Motorcycle }=4 ; \text { Non-motorised } \\
\text { transport }=5)\end{array}$ \\
\hline P16 & $\begin{array}{l}\text { Purpose of main trip (working/studying }=1 ; \text { social } \\
\text { activity \& shopping }=2 ; \text { exercise/religious/others }=3 \text { ) }\end{array}$ \\
\hline P17 & $\begin{array}{l}\text { Frequency of main trip (everyday }=1 ; 2 \text { or } 3 \text { times in a } \\
\text { week }=2 ; \text { once a week }=3 ; 2 \text { or } 3 \text { times in a month } \& \\
\text { hardly ever }=4 ; \text { once a month }=5 \text { ) }\end{array}$ \\
\hline P18 & $\begin{array}{l}\text { Experiences on traffic safety education at school (Yes }=1 \text {; } \\
\text { No }=2)\end{array}$ \\
\hline II. & Traffic safety tips \\
\hline $\mathrm{P} 21$ & $\begin{array}{l}\text { Understanding traffic rules (pedestrian crossing/bridge }= \\
1 ; \text { pedestrian signal/reflective items/cyclists on left } \\
\text { side=2) }\end{array}$ \\
\hline $\mathrm{P} 22$ & $\begin{array}{l}\text { Practices usually observed for traffic safety (following } \\
\text { the pedestrian traffic signals (not walking through a red- } \\
\text { light }=1 \text {; not crossing a road and intersection without } \\
\text { pedestrian crossing or bridge }=2 \text {; making proper use of the } \\
\text { footpaths }=3 \text {; taking extra caution before road } \\
\text { crossing/wear reflective items }=4 \text { ) }\end{array}$ \\
\hline III. & Pedestrian accidents measures \\
\hline P31 & $\begin{array}{l}\text { Location of pedestrians' accident }(\text { junctions }=1 ; \\
\text { pedestrian crossing }=2 ; \text { footpath }=3 \text { ) }\end{array}$ \\
\hline $\mathrm{P} 32$ & $\begin{array}{l}\text { Mode types as the main cause of traffic accident }(\mathrm{car}=1 \text {; } \\
\text { motorcycle }=2)\end{array}$ \\
\hline $\mathrm{P} 33$ & $\begin{array}{l}\text { Major cause of traffic accidents (careless or inattentive } \\
\text { driving/riding }=1 \text {; traffic violation=2; lack/shortage of } \\
\text { pedestrian facilities }=3 \text { ) }\end{array}$ \\
\hline P34 & $\begin{array}{l}\text { Time of traffic accidents most likely to happen (night } \\
\text { time }=1 ; \text { daytime }=2 ; \text { others }=3 \text { ) }\end{array}$ \\
\hline IV. & Measures are taken to improve traffic safety \\
\hline P41 & Measures are taken to improve traffic safety \\
\hline P42 & Groups in need of traffic education \\
\hline
\end{tabular}

As shown in Table 1, the questionnaire consists of four sections and a total of 16 main questions. The data relating to pedestrians' perceptions of traffic safety and respondents' socio-demographic factors, were collected. Besides, pedestrian perceptions on measures taken to improve traffic safety were identified. Pedestrian perceptions towards traffic safety were measured by their knowledge and awareness of transport safety and traffic accidents measures. The 
respondents were asked to choose the answers for the questionnaire questions; also, they were allowed to choose more than one answer.

\section{B. Discrete Choice Models}

The multinomial logit model (MNLM) is a statistical method used to predict class relationships' probability on a predicted variable constructed on several predictor variables [22]. The expected variable in question is nominal and for which there are more than two categories, while the predictor variables can be either dichotomous or continuous. The method is used to predict nominal response variables by representing the log odds of the responses are represented as a linear grouping of the explanatory variables. The MNLM is an upgrade version of binary logit regression that tolerates two or more categories of the outcome variable. Like binary logit regression, the MNLM applies maximum likelihood estimation to appraise the chance of categorical membership. MNLMs have restrictive assumptions of independence, normality, and multicollinearity.

For categories $i=2 \ldots K$, the probability of category $i$ can be written as follows:

$$
\operatorname{Pr}(Y=i)=\frac{\exp \left(Z_{i}\right)}{1+\sum_{h=2}^{K} \exp \left(Z_{h i}\right)}
$$

where, category,

$$
\alpha_{i}+\sum_{h=1}^{H} \quad \beta_{i h} x_{i h}=Z_{i .} \text { in which for the reference }
$$

$$
\operatorname{Pr}(Y=1)=\frac{1}{1+\sum_{h=2}^{K} \exp \left(Z_{h i}\right)}
$$

Equations (1) and (2) are rearranged so the MNL model can be expressed as follows:

$$
\operatorname{Ln}\left(\frac{P(Y=i)}{P(Y=1)}\right)=\alpha_{i}+\sum_{h=1}^{H} \quad \beta_{i h} X_{i h}=Z_{i}
$$

where,

$\beta_{i h}, X_{i h}$ : vectors of the estimated parameters and predictor variables respectively

$\underline{P(Y=i)}$ : the probability of pedestrian injuries either fatal, $\overline{P(Y=1)}$. serious injury or slight injury with the first category as the reference.

$i$ : the number of injury categories

The equation above stated the logit (log odds) as a linear function of the predictors (Xs). When there are only two dependent outcomes, it is named as binary logit model. Logistic regression is employed to estimate a function with a binary dependent variable in this study. The dependent variable is the probability $(\mathrm{P})$ of the population in which the outcome is equal to one (1). Predictor variables produce parameters that can be employed to predict odds ratios for each of the predictors in the model [23]. The logistic regression model is expressed as follows:

$$
\pi(x)=P=\frac{e^{\beta_{o}+\beta_{1} x}}{1+e^{\beta_{o}+\beta_{1} x}}
$$

The logit is transforming the conditional mean $\pi(\mathrm{x})$ using the $L N$ (to base $e$ ) of the odds, or the likelihood ratio that the dependent variable is one (1), such that,

$$
\operatorname{Logit}(P)=\operatorname{Ln}\left(\frac{P_{i}}{1-P_{i}}\right)=\beta_{o}+\beta_{i} \cdot X_{i}
$$

where,

$X_{i}$ : set of independent variables $(i=1,2, \ldots \ldots \ldots, n)$

$P$ : probability ranges from 0 to 1

$\beta_{i}$ : the parameter estimates for the independent variables

$\beta_{o}$ : the model constant

$\left(\frac{P_{i}}{1-P_{i}}\right):$ the natural logarithm ranges

On the assumption that the predictor $\mathrm{X}$ increases by one (1) unit and the other variables stay constant, the odds $\left[P_{i} /(1-\right.$ $\left.P_{i}\right)$ ] rises by a factor 7 This is defined as the odds ratio (OR). It varies from 0 to positive infinity and specifies whether the odds are either increasing $(\mathrm{OR}>1)$ or decreasing $(\mathrm{OR}<1)$. In addition, there is no real regression coefficient $\left(R^{2}\right)$ in a logistic regression model. Alternatively, Cox and Snell Pseudo- $\mathrm{R}^{2}$ and Nagelkerke Pseudo- $\mathrm{R}^{2}$ can be employed as a proxy of an $\mathrm{R}^{2}$ :

$$
\text { Cox \& Snell Pseudo- } \mathrm{R}^{2}=\mathrm{R}^{2}=1-\left[\frac{-2 L L_{n u l l}}{-2 L L_{k}}\right]^{2 / n}
$$

The Cox \& Snell pseudo- $\mathrm{R}^{2}$ would not achieve the value of one (1); therefore, Nagelkerke is employed to modify it as follows:

$$
\text { Nagelkerke Pseudo- } \mathrm{R}^{2}=\mathrm{R}^{2}=\frac{1-\left[\frac{-2 L L_{n u l l}}{-2 L L_{k}}\right]^{2 / n}}{1-\left(-2 L L_{n u l l}\right)^{2 / n}}
$$

The goodness of fit of the model is measured with a Hosmer-Lemeshow (H-L) Test. If the model fits or does not fit the data, this represents either null or alternative hypotheses, respectively. The H-L test is as follows:

$$
\hat{C}=\sum_{k=1}^{g} \frac{\left(O_{k}-E_{k}\right)^{2}}{v_{k}}
$$

where,

$O_{\mathrm{k}}$ : Observed number of events

$E_{\mathrm{k}}$ : Expected number of events

$v_{\mathrm{k}}$ : Variance correction factor

$\hat{C}$ : The H-L test

Evidence against the null hypothesis will be obtained from the large value of the H-L test. This occurs when the observed numbers of events diverge from the model expectation.

\section{Data Analysis using Discrete Choice Modelling Methods}

As mentioned earlier, this study explores the pedestrians' perceptions and their awareness of road safety. Research questions were drawn to investigate the multiple relationships amongst the measures shown in Table 1 as follows:

- $\mathrm{RQ}_{1}$ : Socio-demographic factors influence pedestrians' perceptions of road safety

- $\mathrm{RQ}_{2}$ : Travel exposure and traffic safety measures affect pedestrians' perceptions of road safety

The model has based on the research questions that the pedestrians are the decision-makers regarding their choice of satisfactory facilities to cross the street. Table 2 shows a matrix of pedestrians' perception towards measures of pedestrian accidents. Each column indicates dependent variables consisting of P31 (location of pedestrians' accidents involving junctions, pedestrian crossings, and 
footpaths), P33 (a major cause of traffic accidents considering careless/inattentive driving/riding, traffic violation and lack/shortage of pedestrian facilities) and P34 (time of traffic accidents most likely to happen including night time, daytime and others). P31, P33 and P34 were modelled with Multinomial Logit (MNL) methods. In contrast, P32, relating to pedestrian views of the type of mode more likely to be involved in a traffic accident. Since the modes are car and motorcycle, Binary Logit (BL) methods were applied when analysis P32.

The higher goodness of fit (expressed with pseudo- $\mathrm{R}^{2}$ value), the better the fitting of the MNL models [23]. In contrast, such measures are frequently disregarded, as there has been no conventional goodness of fit for these types of models [24]. Alternatively, the classification accuracy is employed to examine the model accuracy. The proportional by the chance of the data accuracy rate was determined with the proportion of each category within a dependent variable. The overall classification accuracy rate, for example, a variable of P31 (pedestrian perception of accident-prone location: junctions, pedestrian crossing, and footpath) is $46.1 \%$ which is higher than the proportional by chance accuracy criteria of $33.73 \%$ (Refer Tables 2 and 3). As a result, the criteria of model classification accuracy is satisfied (refers to Table 4).

TABLE II

DAta Proportion of Pedestrian PERCEPTIONS of ACCIDENT-PRone LOCATIONS

\begin{tabular}{|c|c|c|c|}
\hline Accident-prone locations & $\begin{array}{c}\text { Number of } \\
\text { Samples }\end{array}$ & Percentage & $\begin{array}{c}\text { Percentage } \\
\text { squared }\end{array}$ \\
\hline Junctions (code = 1) & 81 & $29.9 \%$ & $8.94 \%$ \\
\hline $\begin{array}{c}\text { Pedestrian crossing (code } \\
=3 \text { ) }\end{array}$ & 104 & $38.4 \%$ & $14.75 \%$ \\
\hline Footpath (code = 5) & 86 & $31.7 \%$ & $10.05 \%$ \\
\hline & Total =271 & & $\begin{array}{c}\text { Total }= \\
3.73 \%\end{array}$ \\
\hline
\end{tabular}

Table 3 shows the $\mathrm{R}^{2}$ measures of Cox \& Snell and Nagelkerke. Cox \& Snell $\mathrm{R}^{2}$ normally has the highest value less than one, so that is commonly using Nagelkerke $\mathrm{R}^{2}$. The reason is that Nagelkerke $R^{2}$ divides Cox \& Snell $R^{2}$ with the maximum value to give a measuring range between zero (0) and one (1). For example, the P32 (mode types as the main cause of traffic accidents) model explains $17 \%$ of the outcome variation. Besides, the Hosmer-Lemeshow (H-L) test demonstrates that the logistic regression models are statistically significant ( $\mathrm{p}$-value $>0.05$ ).

TABLE III

OVERALl ClASSIFICATION RATE

\begin{tabular}{|c|c|c|c|c|}
\hline \multirow{2}{*}{ Observed } & \multicolumn{4}{|c|}{ Predicted } \\
\cline { 2 - 5 } & $\begin{array}{c}\text { Junctions } \\
(1)\end{array}$ & $\begin{array}{c}\text { Pedestrian } \\
\text { crossing (3) }\end{array}$ & $\begin{array}{c}\text { Footpath } \\
(5)\end{array}$ & $\begin{array}{c}\text { Percent } \\
\text { Correct }\end{array}$ \\
\hline Junctions (1) & 13 & 49 & 19 & $16.0 \%$ \\
\hline $\begin{array}{c}\text { Pedestrian } \\
\text { crossing (3) }\end{array}$ & 9 & 70 & 25 & $67.3 \%$ \\
\hline Footpath (5) & 5 & 39 & 42 & $48.8 \%$ \\
\hline $\begin{array}{c}\text { Overall } \\
\text { Percentage }\end{array}$ & $10.0 \%$ & $58.3 \%$ & $31.7 \%$ & $46.1 \%$ \\
\hline
\end{tabular}

TABLE IV

MODEL VALIDITY

\begin{tabular}{|c|c|c|c|c|}
\hline Model & $\begin{array}{c}\text { Data } \\
\text { Observed }\end{array}$ & $\begin{array}{c}1.25 * \text { Data } \\
\text { Observed }\end{array}$ & $\begin{array}{c}\text { Model } \\
\text { Results }\end{array}$ & $\begin{array}{c}\text { Model } \\
\text { Accuracy }\end{array}$ \\
\hline $\begin{array}{c}\text { MNL } \\
\text { P31 }\end{array}$ & $33.73 \%$ & $42.17 \%$ & $46.1 \%$ & Satisfied \\
\hline $\begin{array}{c}\text { MNL } \\
\text { P33 }\end{array}$ & $44.92 \%$ & $56.16 \%$ & $62.3 \%$ & Satisfied \\
\hline $\begin{array}{c}\text { MNL } \\
\text { P34 }\end{array}$ & $36.82 \%$ & $46.03 \%$ & $52.3 \%$ & Satisfied \\
\hline H-L Test & $\begin{array}{c}\text { Cox \& Snell } \\
\mathrm{R}^{2}\end{array}$ & $\begin{array}{c}\text { Nagelkerke } \\
\mathrm{R}^{2}\end{array}$ & \\
\hline $\begin{array}{c}\text { BL } \\
\text { P32 }\end{array}$ & 0.51 & 0.12 & 0.17 & \\
\hline
\end{tabular}

Notes:

- P31: Location of pedestrians' accident involving junctions, pedestrian crossing, and footpath).

- P32: Mode types consisting of car and motorcycle as the main cause of traffic accident).

- P33: Major causes of traffic accidents considering careless/inattentive driving/riding, traffic violation and lack/shortage of pedestrian facilities).

- P34: Time of traffic accidents most likely to happen to contain night time, daytime and others)

\section{RESULTS AND DISCUSSION}

The estimated results of the MNL models (P31, P33, and P34) and BL model (P32) are presented in Table 5. More specifically, all models explain that socio-demographic factors (attached to $R Q_{1}$ ), as well as travel exposures and traffic safety measures (attached to RQ2), are highly instrumental for pedestrians' perceptions towards road safety. This has led to the acceptance of the two research questions, $\mathrm{RQ}_{1}$ and $\mathrm{RQ}_{2}$, which were set in the initial stage of the study.

In addition, the alternative specific constants in all four models tend to be relatively small in value compared to the other coefficients in many occasions, indicating that the predictors used in the models are appropriate as they account for a larger proportion when accumulating pedestrians' perception towards road safety. The subsections below explain the results for each model.

\section{MNL model - P31:}

Location of pedestrians' accident (junctions = 1 ; pedestrian crossing $=2$; footpath $=3$ )

- The reference category was considered as "footpath" for this MNL model.

- The significant and positive coefficient $(\beta=1.07)$ for the driving license category indicates that pedestrians with driving licenses perceive that junctions are not as safe as footpaths, in terms of the location of road traffic accidents. This means that the odds for pedestrians with a driving license over the odds for pedestrians without a driving license is $2.92\left(\mathrm{OR}=\exp ^{1.07}\right)$. In terms of percent change, the odds for driving license holders are $192 \%$ higher than the odds for those who do not own driving licenses. This is consistent with a past study [7] which clearly states that most pedestrian accidents take place at junctions.

- In addition, even though pedestrians take extra care by complying with traffic signals at pedestrian crossings, 
they still do not feel safe at pedestrian crossings compared to the reference category of "footpaths." The relevant coefficient was statistically significant at the $95 \%$ confidence level with a value of 0.95 . Pedestrian crossings are shared among all road users and therefore are locations where the safety of pedestrians is compromised [9].

\section{BL model - P32:}

Mode types as the main cause of traffic accident (car = 1; motorcycle $=2$ )

- The reference category was considered as "motorcycle" for this BL model.

- Pedestrians aged between 30 and 39 years do not perceive that cars are the main cause for accidents when compared to motorcycles, as the relevant coefficient is negative and significant at $95 \%$ confidence level $(\beta=-2.46)$. Furthermore, in terms of the OR, being a pedestrian belong to the age group 4049 (a unit increase) indicates that the odds of perceiving cars as an unsafe mode over motorcycles is 0.085 . In other words, increasing age group by one unit would decrease the odds by $91.5 \%$.

- The negative and significant coefficient $(\beta=-1.43)$, for taking extra care by complying with traffic signals at pedestrian crossings, indicates that the pedestrians perceive that it is less likely that cars are the main cause for accidents when compared to motorcycles.

\section{MNL model - P33:}

Major cause of traffic accidents (careless or inattentive driving/riding=1; traffic violation=2; lack/shortage of pedestrian facilities $=3$ )

- The reference category was considered as "lack/shortage of pedestrian facilities" for this MNL model.

- The results indicate that pedestrians using motorcycles as the primary mode of travel perceived that careless or inattentive driving/riding is a major cause of pedestrian accidents compared to lack/shortage of pedestrian facilities $(\beta=1.34$; $\mathrm{OR}=3.82)$. This can be interpreted as the odds for motorcycle users are $282 \%$ higher than the odds for car drivers.

- The pedestrians capitalizing on "pedestrian traffic signals" and "take extra caution when crossing a road and intersection without pedestrian crossing/bridge" and "make proper use of footpath", perceive that human errors (e.g. careless driving or riding or traffic violation) would be a major cause of accident compared to the non-existence of adequate infrastructure (e.g. lack of pedestrian facilities). This is in line with a past study that outlined that reckless and careless driving was responsible for nearly one-half of all pedestrian accidents [25].

\section{MNL model - P34:}

Time of traffic accidents most likely to happen (night time $=1 ;$ daytime $=2 ;$ others $=3$ )
- The reference category was considered as "others" for this MNL model.

- The findings of this model indicate that pedestrians with an income of less than 3 million rupiahs, as well as more than or equal to 3 million rupiahs, perceived that night time are 7.84 and 2.53 times respectively more significant than other times of day, for pedestrian accidents. In addition, pedestrians with an income of less than 3 million rupiahs and more and equal to 3 million rupiahs considered that day time are 4.30 and 2.32 times respectively more significant than other times of day, for pedestrian accidents. It is noted that 3 million rupiahs is approximately the regional minimum wage of Denpasar city (1 US $\$=14,000$ rupiahs).

- Pedestrians exposed to traffic safety education at school perceived that pedestrian accidents may happen both at night time and at day time, as the model generated positive and significant coefficients, 1.23 (at 95\% significant level) and 1.97 (at 99\% significant level) respectively. The slightly larger coefficient for day time than night time may be due to the consideration of the higher pedestrian flow in the day time, by the respondents.

- Pedestrians who follow the traffic rules on pedestrian crossing/bridge perceived that pedestrian accidents are more likely to happen at night time as the relevant coefficient is positive and significant $(\beta=0.98)$ than others as time of pedestrian accidents. A previous study also showed the association of darkness, and its contribution to pedestrian accidents [26].

Based on Figure 1, the results indicated that the probability of junctions, pedestrian crossings and footpaths considered as the location of pedestrians' accidents (P31) is $43 \%, 41 \%$ and $16 \%$ respectively. A previous study conducted in Malaysia also confirms our findings that junctions and pedestrian crossings are significantly considered as the prone location of high pedestrian injuries [27].

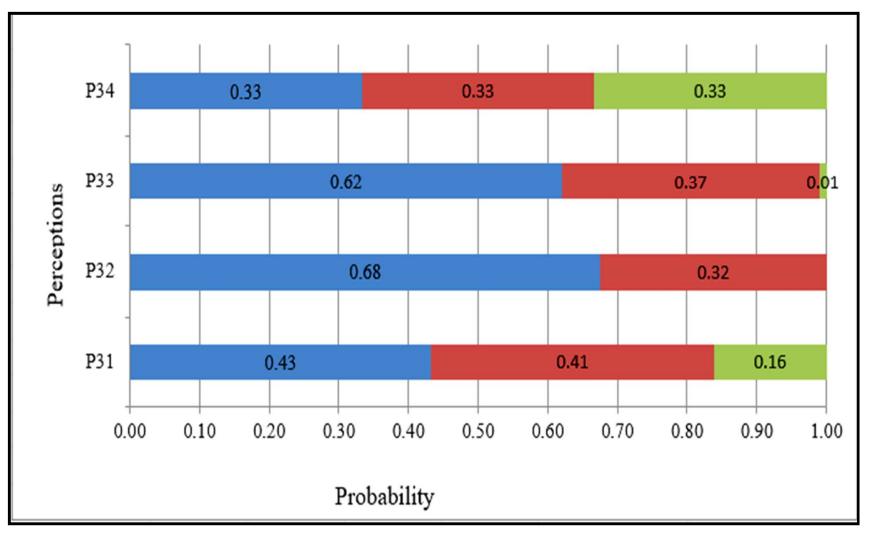

Fig. 1 Shares for each category included in the statements P31, 32, 33 and 34 
TABLE V

INFLUENCING FACTORS ON PEDESTRIAN PERCEPTION TOWARDS ROAD SAFETY

\begin{tabular}{|c|c|c|c|c|c|c|c|}
\hline \multirow{3}{*}{ Variables } & \multicolumn{2}{|l|}{ MNL model - P31 } & \multirow{3}{*}{$\begin{array}{l}\text { BL model - P32 } \\
\text { Main mode of transport } \\
\text { Car }\end{array}$} & \multicolumn{2}{|l|}{ MNL model - P33 } & \multicolumn{2}{|l|}{ MNL model - P34 } \\
\hline & \multicolumn{2}{|c|}{ Pedestrian accident locations } & & \multicolumn{2}{|c|}{ Major cause of pedestrian accidents } & \multicolumn{2}{|c|}{ Time of pedestrian accidents } \\
\hline & Junction & Pedestrian crossing & & Careless & Traffic violation & Night time & Day time \\
\hline Constant & $(-1.37 *)$ & $(-0.71)$ & $(0.17)$ & $(-0.19)$ & $(-0.99 *)$ & $(-1.83 *)$ & $(-0.97)$ \\
\hline Age & -- & -- & $\begin{array}{l}\text { 30-39 years } \\
(-2.46 *)\end{array}$ & -- & -- & $\begin{array}{l}30-39 \text { years } \\
(0.54)\end{array}$ & $\begin{array}{l}\text { 30-39 years } \\
(-0.81)\end{array}$ \\
\hline Household income & -- & -- & $\begin{array}{l}<3 \mathrm{~m} \text { rupiahs } \\
(0.79) \\
\geq 3 \mathrm{~m} \text { rupiahs } \\
(0.61)\end{array}$ & -- & -- & $\begin{array}{l}<3 \mathrm{~m} \text { rupiahs } \\
(\mathbf{2 . 0 6} * *) \\
\geq 3 \mathrm{~m} \text { rupiahs } \\
(\mathbf{0 . 9 3} *)\end{array}$ & $\begin{array}{l}<3 \mathrm{~m} \text { rupiahs } \\
\left.(\mathbf{1 . 4 6})^{*}\right) \\
\geq 3 \mathrm{~m} \text { rupiahs } \\
\left.(\mathbf{0 . 8 4})^{*}\right)\end{array}$ \\
\hline $\begin{array}{l}\text { Driving license } \\
\text { ownership }\end{array}$ & $\begin{array}{l}\text { yes } \\
(\mathbf{1 . 0 7} *)\end{array}$ & $\begin{array}{l}\text { yes } \\
(0.46)\end{array}$ & $\begin{array}{l}\text { yes } \\
(-0.93)\end{array}$ & -- & -- & -- & -- \\
\hline $\begin{array}{l}\text { Primary mode of } \\
\text { travel }\end{array}$ & -- & -- & $\begin{array}{l}\text { motorcycle } \\
(0.84)\end{array}$ & $\begin{array}{l}\text { motorcycle } \\
(\mathbf{1 . 3 4} *)\end{array}$ & $\begin{array}{l}\text { motorcycle } \\
(1.03)\end{array}$ & $\begin{array}{l}\text { motorcycle } \\
(-0.75)\end{array}$ & $\begin{array}{l}\text { motorcycle } \\
(-0.17)\end{array}$ \\
\hline $\begin{array}{l}\text { Experiences on } \\
\text { traffic safety } \\
\text { education at school }\end{array}$ & -- & -- & $\begin{array}{l}\text { yes } \\
(0.19)\end{array}$ & -- & -- & $\begin{array}{l}\text { yes } \\
(\mathbf{1 . 2 3} *)\end{array}$ & $\begin{array}{l}\text { yes } \\
(1.97 * *)\end{array}$ \\
\hline $\begin{array}{l}\text { Understanding } \\
\text { traffic rules }\end{array}$ & -- & -- & $\begin{array}{l}\text { pedestrian crossing/bridge } \\
\text { (1.01) }\end{array}$ & -- & -- & $\begin{array}{l}\text { pedestrian } \\
\text { crossing/bridge }(0.98 *)\end{array}$ & $\begin{array}{l}\text { pedestrian } \\
\text { crossing/bridge } \\
(0.49)\end{array}$ \\
\hline $\begin{array}{l}\text { Practices usually } \\
\text { observed for traffic } \\
\text { safety }\end{array}$ & $\begin{array}{l}\text { following pedestrian } \\
\text { traffic signal } \\
(0.75) \\
\\
\text { not crossing a road } \\
\text { and intersection } \\
\text { without pedestrian } \\
\text { crossing/bridge }(0.77) \\
\\
\text { making proper use of } \\
\text { footpath } \\
(-0.24)\end{array}$ & $\begin{array}{l}\text { following pedestrian } \\
\text { traffic signal } \\
(\mathbf{0 . 9 5}) \\
\\
\text { not crossing a road } \\
\text { and intersection } \\
\text { without pedestrian } \\
\text { crossing/bridge } \\
(0.65) \\
\\
\text { making proper use of } \\
\text { footpath } \\
(-0.43) \\
\end{array}$ & $\begin{array}{l}\text { following pedestrian } \\
\text { traffic signal } \\
(\mathbf{- 1 . 4 3} *) \\
\\
\text { not crossing a road } \\
\text { and intersection } \\
\text { without pedestrian } \\
\text { crossing/bridge } \\
(0.51) \\
\\
\text { making proper use } \\
\text { of footpath } \\
(0.90)\end{array}$ & $\begin{array}{l}\text { following pedestrian } \\
\text { traffic signal } \\
\left(\mathbf{2 . 3 6} \mathbf{H}^{*}\right) \\
\text { not crossing a road } \\
\text { and intersection } \\
\text { without pedestrian } \\
\text { crossing/bridge ( } 0.57) \\
\text { making proper use of } \\
\text { footpath } \\
\left(\mathbf{1 . 6 5}^{*}\right)\end{array}$ & $\begin{array}{l}\text { following pedestrian } \\
\text { traffic signal } \\
(\mathbf{2 . 1 0} * *) \\
\\
\text { not crossing a road } \\
\text { and intersection } \\
\text { without pedestrian } \\
\text { crossing/bridge } \\
(\mathbf{1 . 4 2} *) \\
\text { making proper use of } \\
\text { footpath } \\
(\mathbf{1 . 4 9 * )}\end{array}$ & $\begin{array}{l}-- \\
- \\
--\end{array}$ & -- \\
\hline
\end{tabular}

Notes: ** significantly different from zero at the 0.01 level; * significantly different from zero at the 0.05 level 
Notes:

P31: Location of pedestrians' accident (junctions $=1$ $(43 \%)$; pedestrian crossing $=2(41 \%)$; footpath $=3$ $(16 \%))$

P32: Mode types as the main cause of traffic accident $($ car $=1(47 \%) ;$ motorcycle $=2(53 \%))$

P33: $\quad$ Major cause of traffic accidents (careless or inattentive driving/riding $=1 \quad(62 \%) ; \quad$ traffic violation $=2(37 \%)$; lack/shortage of pedestrian facilities $=3(1 \%))$

P34: Time of traffic accidents most likely to happen (night time $=1(33 \%)$; daytime $=2(33 \%)$; others $=3$ $(33 \%))$

The probability of cars and motorcycles perceived as the main mode of transport causing pedestrian traffic accidents (P32) is $47 \%$ and $53 \%$ respectively. A study in Malaysia also shows that cars and motorcycles significantly contributed to pedestrian traffic accidents, involving singlevehicle accidents with single-pedestrian casualties [27].

The probability of careless or inattentive driving perceived as a major cause of traffic accidents (P33) is $62 \%$, followed by traffic violation (37\%) and lack/shortage of pedestrian facilities $(1 \%)$. A prior study in Indonesia, also found that disobedient behavior and careless driving were among the main reasons for traffic accidents [28]. In addition, all categories (night time, day time and others) considered as time of pedestrian traffic accidents most likely to happen (P34) shares an equal probability around 33\%.

Meanwhile, the pedestrians are also allowed to choose more than one measure for each statement in the questionnaire (P41-measures taken to improve traffic safety). As the result, pedestrians perceived that "improving traffic signals, pedestrian crossings, and street lights", "banning onstreet parking", "speed limit enforcement for drivers and riders", "traffic education to drivers" and "traffic education to pedestrians" at $58.39 \%, 47.74 \%, 35.16 \%, 21.29 \%$ and $15.16 \%$ respectively, would be important activities to be able to improve road safety in Denpasar, Bali. This is in line with past studies $[18,26]$ providing good pedestrian facilities and road infrastructure, including footways, pedestrian crossings, and street lighting, which can accommodate pedestrian safety. Meanwhile, a past study indicated that lack of traffic rules and regulation enforcement, and limited road user education program, may result in a disproportionately high number of pedestrian injuries and fatalities [29]. This indicates that enhancing pedestrian safety should be looked at in an integrated manner with attention to all aspects of engineering, policy, enforcement, as well as safety education programs.

In addition, pedestrians are interviewed using the questionnaire and are expected to identify road users who need to have traffic education (P42). Based on the information from the questionnaire, pedestrians identified groups of road users need to have traffic education, including all motorists $(67.10 \%)$, pedestrians of school students $(17.10 \%)$, motorcyclists $(13.87 \%)$, car drivers $(10.97 \%)$, pedestrians (adult) $(10.32 \%)$, bus drivers $(5.16 \%)$, truck drivers $(2.58 \%)$ and bicyclists (1.61\%).

\section{IV.CONCLUSION}

Pedestrians' perceptions of pedestrian accidents and safety were analyzed, and possible measures to improve pedestrian traffic safety in Denpasar and Bali were identified. This study found that junctions and motorcycles were considered more responsible than roadways and cars respectively, to influence pedestrian accidents.

This study outlined that reckless and careless behavior during driving and riding was responsible for pedestrian accidents. Pedestrians with high and low incomes perceived that both night and day times are significant when pedestrian accidents occur. Pedestrians who had previous experiences on traffic safety education at school also perceived that night and day times are significant times of day for pedestrian accidents. Meanwhile, the pedestrians that adhere to traffic protocols at pedestrian crossings and bridges considered that night time is more significant than other times of day, for pedestrian accidents.

In order to respond to the study findings, the measures considered are relevant to enhance pedestrian safety in Denpasar, Bali. These measures have covered the aspects of engineering, policy, enforcement, and education. This includes improving road infrastructure (traffic signaling, pedestrian crossings, street lights, etc.), banning on-street parking, speed limit enforcement for drivers and riders, traffic education to drivers and pedestrians. Moreover, this study highlights that all motorists are recommended to be exposed to traffic education.

\section{ACKNOWLEDGEMENT}

We would like to express our gratitude to the Udayana University for supporting us to undertake the study.

\section{REFERENCES}

[1] United Nations. (2018) World Urbanization Prospects: The 2018 Revision. [Online]. Available: https://population.un.org/wup/publications/files/wup2018keyfacts.pdf.

[2] R.E. Cookson, D.C. Richards, and R.W. Cuerden, "The characteristics of pedestrian road traffic accidents and the resulting injuries," TRL Insight Report INS009, 2011.

[3] J. Aryaija, D. Dissanayake, D.M.P. Wedagama, and R.N. Bird, "Land use factors and the risk for child pedestrians," Journal of the Eastern Asia Society for Transportation Studies., vol. 7, pp. 28142829, Dec. 2007.

[4] D. Dissanayake, J. Aryaija, and D.M.P. Wedagama, "Modelling the effects of land use and temporal factors on child pedestrian casualties," Accident Analysis and Prevention., vol. 41, no.5, pp. 016- 1024, Sept. 2009.

[5] H. Wang, D.C. Schwebel, D. Tan, L. Shi, and L. Miao, "Gender differences in children's pedestrian behaviors: developmental effects," Journal of Safety Research., vol. 67, pp. 127-133, Dec. 2018.

[6] E. Papadimitriou, A. Theofilatos, G. Yannis, G.M. Sardi, and R. P. J Freeman, "Road safety attitudes and perceptions of pedestrians in Europe," Procedia-Social and Behavioural Sciences., vol. 48, pp. 2490-2900, July, 2012.

[7] S. Marisamynathan, and P. Vedagiri, "Estimation of pedestrian safety index value at signalised intersections under mixed traffic conditions," Transportation in Developing Economies., vol. 4, no. 5, pp. 1-11, April, 2018.

[8] I. Mateo-Babiano, "Pedestrian's needs matter: examining Manila's walking environment," Transport Policy., vol. 45, pp.107-115, Jan, 2016.

[9] H.M. Kim, and I. Mateo-Babiano, "Pedestrian crossing environments in an emerging Chinese city: vehicle encountering, seamless walking, 
and sensory perception perspectives," Sustainability., vol. 10, no. 7, pp. 1-17, June, 2018.

[10] J. Speck, Walkable City: How Downtown Can Save America, One Step at A Time. New York, USA: Farrar, Straus and Giroux, 2012.

[11] World Health Organization, Global Status Report on Road Safety. Geneva, Switzerland: World Health Organization, 2015.

[12] E. Howard, Road Casualties in Indonesia: The Silent Epidemic. Jakarta, Indonesia: Indonesia Infrastructure Initiative (INDII), SMEC International, 2015.

[13] G. Yannis, G. Kanllaidis, J. Dimitropoulos, and N. Muhlrad, "Assessment of pedestrian safety measures in Europe," ITE Journal., vol. 77, no. 12, pp. 40-48, Dec, 2007.

[14] M.A. Granie, "Gender differences in preschool children's declared and behavioural compliance with pedestrian rules," Transportation Research Part F., vol.10, pp. 371-382, July, 2007.

[15] I.M. Bernhoft, G. Carstensen, "Preferences and behaviours of pedestrian and cyclists by age and gender," Transportation Research Part F., vol.11, pp. 83-95, Mar, 2008.

[16] H. Guo, F. Zhao, W. Wang, Y. Zhou, Y. Zhang, and G. Wets, "Modeling the perceptions and preferences of pedestrians on crossing facilities," Discrete Dynamics in Nature and Society., Article ID 949475, pp. 1-8, Mar, 2014.

[17] G.S. Tulu, S. Washington, M.J. King, and Md. M. Haque, "Why are pedestrian crashes so different in developing countries? a review of relevant factors in relation to their impact in Ethiopia," in 36th Australasian Transport Research Forum (ATRF): Transport and the New World City, 2013, pp. 1-18.

[18] P.R. Anciaes, and P. Jones, "Estimating preferences for different types of pedestrian crossing facilities," Transportation Research Part F: Traffic Psychology and Behaviour., vol. 52, pp. 222-237, Jan, 2018.

[19] D. Kahlert, and W. Schlicht, "Older people's perceptions of pedestrian friendliness and traffic safety: an experiment using computer-simulated walking environments," International Journal of Environment Research and Public Health., vol. 12, pp. 10066-10078, Aug, 2015.
[20] S.A. Hanan, N. F. Said, A. A. M. Kamel, and S. A. F. C. Amil, "Factors that influences pedestrian intention to cross a road while using mobile phone," International Journal of Economics and Financial Issues., vol. 5, pp. 116-121, Aug, 2015.

[21] P. Ulleberg, and T. Rundmo, "Personality, attitudes and risk perception as predictors of risky driving behaviour among young drivers," Safety Science., vol. 41, pp. 427-443, June, 2003.

[22] R. Williams. (2018) Multinomial Logit Models - Overview. [Online] Available: https://www3.nd.edu/ rwilliam/stats3/Mlogit1.pdf

[23] S.P. Washington, M. G. Karlaftis, and F. L. Mannering, Statistical and Econometric Methods for Transportation Data Analysis. New York, USA: Chapman \& Hall, 2003.

[24] C.J. O'Donnel, and D. H. Connor, "Predicting the severity of motor vehicle accident injuries using models of ordered multiple choice," Accident Analysis and Prevention., vol. 28, no. 6, pp. 739 - 753 , Nov, 1996.

[25] J.A. Boni, T. R. Chowdhury, and S. S. Das, "A Study on causes of road accidents at Dhaka to Comilla highway," Asian Journal of Innovative Research in Science, Engineering and Technology (AJIRSET)., vol. 1, no. 9, pp. 6-13, Oct, 2016.

[26] X. Yao, J. Guo, C. Ren, and X. Wang, "The Influence of urban road lighting on pedestrian safety," International Journal of Engineering Innovation \& Research., vol. 7, no. 2, pp. 136-138, Mar, 2018.

[27] A.H. Ariffin, Z. M. Jawi, M. H. Isa, K.A.A. Kassim, and W. S. Voon, "Pedestrian casualties in road accidents-Malaysia perspective," in 1st MIROS Road Safety Conference (ROSCON), 2010, pp. 280-289.

[28] S.P. Santosa, A.I. Mahyuddin, and F.G. Sunoto, "Anatomy of injury severity and fatality in Indonesian traffic accidents," Journal of Engineering and Technological Sciences., vol. 49, no. 3, pp. 412-422, Aug, 2017.

[29] A. Fransman, B. Richter, and S. Raath, "An interactive computer program for South African urban primary school children to learn about traffic signs and rules," A Journal of Injury and Violence Prevention., vol. 16, no. 1, pp. 57-67, Oct, 2018. 